Tersedia online di: http://ejournal-balitbang.kkp.go.id/index.php/JP
e-mail:jurnalpari@gmail.com
JURNAL PARI
Volume 3 Nomor 2 Desember 2017
p-ISSN: 2502-0730
e-ISSN : 2549-0133

\title{
PEMBUATAN SISTEM INFORMASI SURAT PERINTAH PERJALANAN DINAS PADA PUSAT RISET KELAUTAN
}

The development of information system of a command letter for service travel in marine research centre

\section{DANI SAEPULOH}

Pusat Riset Kelautan, Badan Riset dan Sumber Daya Manusia Kelautan dan Perikanan, KKP Diterima tanggal : 16 Agustus 2017 diterima setelah perbaikan : 22 November 2017 disetujui terbit : 1 Desember 2017

\begin{abstract}
ABSTRAK
Pusat Riset Kelautan (Pusriskel) adalah unit eselon II di bawah Badan Riset dan Sumber Daya Manusia Kelautan dan Perikanan (BRSDMKP), Kementrian Kelautan dan Perikanan (KKP). Pusriskel belum memiliki aplikasi terutama dalam perjalanan dinas. Website yang dimiliki Pusriskel merupakan media online yang berperan sebagai media informasi, media ini lebih banyak memuat informasi pemberitaan. Sedangkan sistem informasi utama yang berkenaan dengan perjalanan dinas itu sendiri belum ada. Selama ini dalam pengerjaan penginputan Surat Perintah Perjalanan Dinas (SPPD) hanya menggunakan Microsoft Excel saja. Pegawai yang mengerjakan tentang berkas dan pertanggungjawaban perjalanan dinas rata-rata sudah berumur atau yang mendekati pensiun, karena kendala untuk permintaan pegawai baru. Sehingga untuk mendapatkan informasi menjadi masalah. Dengan demikian perlu adanya alternatif aplikasi untuk memudahkan pekerjaan bagi pegawai yang mengerjakannya.
\end{abstract}

Kata Kunci: SPPD, Surat Perjalanan, Pusriskel, BRSDM KP, KKP.

\section{ABSTRACT}

Marine Research Center (Pusriskel) is a unit of echelon II under the Research and Human Resources Agency for Marine and Fisheries (BRSDM KP), the Ministry of Maritime Affairs and Fisheries (MMAF). Pusriskel not have any applications particularly in business travel. Website owned Pusriskel an online media that acts as an information medium, this medium contains more news information. While the major information systems relating to official travel itself does not exist. During the execution of inputting Official Travel Warrant (SPPD) only using Microsoft Excel only. Employees who worked on the file and accountability of official travel on average are elderly or who are approaching retirement, due to constraints on the demand for new employees. So as to obtain information become a problem. Thus the need for an alternative application to facilitate the work for employees who work on it.

Keywords: SPPD, Travel Letter, Pusriskel, BRSDMKP, KKP.

Korespondesi penulis:

Jl. Pasir Putih 1 Ancol Timur, Jakarta

Telp : (021) 64711583, Fax : (021) 64711654

Email : d4n1.saepuloh@gmail.com 


\section{PENDAHULUAN}

Keberadaan Kementerian Kelautan dan Perikanan (KKP) harus sensitif terhadap harapan dan tuntutan masyarakat baik lokal maupun nasional. Kementerian ini dibentuk sebagai salah satu langkah pemerintah untuk keluar dari krisis ekonomi yang berkepanjangan (Laporan Akhir Dokpus, 2015). Untuk itu KKP harus mempersiapkan strategi pembangunan, menetapkan kebijakan dan melaksanakan program guna mendukung harapan dan tuntutan tersebut.

Pusat Riset Kelautan (Pusriskel) adalah unit eselon II di bawah Badan Riset dan Sumber Daya Manusia Kelautan dan Perikanan (BRSDMKP), Kementrian Kelautan dan Perikanan (KKP). Pusriskel belum memiliki aplikasi terutama dalam perjalanan dinas. Website yang dimiliki Pusriskel merupakan media online yang berperan sebagai media informasi, media ini lebih banyak memuat informasi pemberitaan. Sedangkan sistem informasi utama yang berkenaan dengan perjalanan dinas itu sendiri belum ada. Selama ini dalam pengerjaan penginputan Surat Perintah Perjalanan Dinas (SPPD) hanya menggunakan Microsoft Excel saja. Pegawai yang mengerjakan tentang berkas dan pertanggungjawaban perjalanan dinas rata-rata sudah berumur atau yang mendekati pensiun, karena kendala untuk permintaan pegawai baru. Sehingga untuk mendapatkan informasi menjadi masalah.

\section{METODOLOGI}

Metode air terjun atau yang sering disebut metode waterfall sering dinamakan siklus hidup klasik (classic life cycle), dimana hal ini menggambarkan pendekatan yang sistematis dan juga berurutan pada pengembangan perangkat lunak, dimulai dengan spesifikasi kebutuhan pengguna lalu berlanjut melalui tahapan-tahapan perencanaan (planning), permodelan (modeling), konstruksi (construction), serta penyerahan sistem ke para pelanggan/pengguna (deployment), yang diakhiri dengan dukungan pada perangkat lunak lengkap yang dihasilkan (Pressman, 2012). Tahapan metode waterfall dapat dilihat pada Gambar 1.

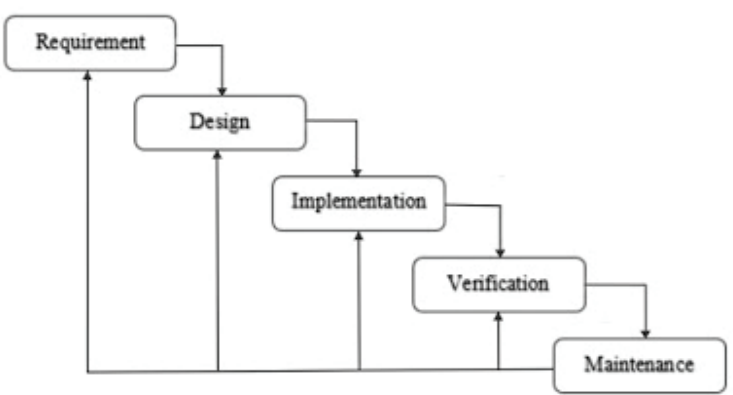

Gambar I Tahapan metode waterfall, Pressman, 2012.

\section{Tahapan Metode Waterfall}

Dalam pengembangannya metode waterfall memiliki beberapa tahapan yang berurut yaitu: requirement (analisis kebutuhan), design system (desain sistem), Coding (pengkodean) \& Testing (pengujian), Penerapan Program, pemeliharaan. Tahapan tahapan dari metode waterfall adalah sebagai berikut :

1. Requirement Analisis

Tahap ini pengembang sistem diperlukan komunikasi yang bertujuan untuk memahami perangkat lunakyang diharapkan oleh pengguna dan batasan perangkat lunak tersebut. Informasi ini biasanya dapat diperoleh melalui wawancara, diskusi atau survei langsung. Informasi dianalisis untuk mendapatkan data yang dibutuhkan oleh pengguna.

2. System Design

Spesifikasi kebutuhan dari tahap sebelumnya akan dipelajari dalam fase ini dan desain sistem disiapkan. Desain Sistem membantu dalam menentukan perangkat keras(hardware) dan sistem persyaratan dan juga membantu dalam mendefinisikan arsitektur sistem secara keseluruhan.

3. Implementation

Pada tahap ini, sistem pertama kali dikembangkan di program kecil yang disebut unit, yang terintegrasi dalam tahap selanjutnya. Setiap unit dikembangkan dan diuji untuk fungsionalitas yang disebut sebagai unit testing.

4. Integration \& Testing

Seluruh unit yang dikembangkan dalam tahap implementasi diintegrasikan ke dalam sistem setelah pengujian yang dilakukan masingmasing unit. Setelah integrasi seluruh sistem diuji untuk mengecek setiap kegagalan maupun kesalahan. 
5. Operation \& Maintenance

Tahap akhir dalam model waterfall. Perangkat lunak yang sudah jadi, dijalankan serta dilakukan pemeliharaan. Pemeliharaan termasuk dalam memperbaiki kesalahan yang tidak ditemukan pada langkah sebelumnya. Perbaikan implementasi unit sistem dan peningkatan jasa sistem sebagai kebutuhan baru.

Dalam model water fall ada kelebihan dan kekurangan (http://www.markijar.com) yaitu:

Kelebihan Waterfall Model:

1. Mudah diaplikasikan.

2. Memberikan template tentang metode analisis, desain, pengkodean, pengujian, dan pemeliharaan.

3. Cocok digunakan untuk produk software yang sudah jelas kebutuhannya di awal, sehingga minim kesalahannya.

\section{Kekurangan Waterfall model:}

1. Waterfall model bersifat kaku sehingga Penanganan perubahan pada saat proses sedang berlangsung menjadi lebih sulit.

2. Terjadinya pembagian proyek menjadi tahaptahap yang tidak fleksibel, karena komitmen harus dilakukan pada tahap awal proses.

3. Customer harus sabar untuk menanti produk selesai, karena dikerjakan tahap per tahap,menyelesaikan tahap awal baru bisa ke tahap selanjutnya.

4. Perubahan ditengah-tengah pengerjaan produk akan membuat bingung team work yang sedang membuat produk.

5. Adanya waktu menganggur bagi pengembang, karena harus menunggu anggota tim proyek lainnya menuntaskan pekerjaannya.

6. Semua kebutuhan sudah terefenisi sejak awal dan Software yang diberikan adalah versi terakhir dari setiap tahap.

\section{Database Management System (DBMS)}

Database Management System adalah kumpulan file yang saling berkaitan bersama dengan program pengelolaannya. Menurut Kadir (2003:17) pengertian DBMS adalah: "Suatu program komputer yang digunakan untuk memasukkan, mengubah, menghapus memanipulasi dan memperoleh data/informasi dengan praktis dan efisien".

\section{HASIL DAN PEMBAHASAN}

\section{Analisis Sistem Berjalan}

Dari hasil analisis sistem berjalan pembuatan surat perintah perjalanan dinas yang berjalan di Pusat Riset Kelautan dapat digambarkan pada bagan alir Gambar 2.

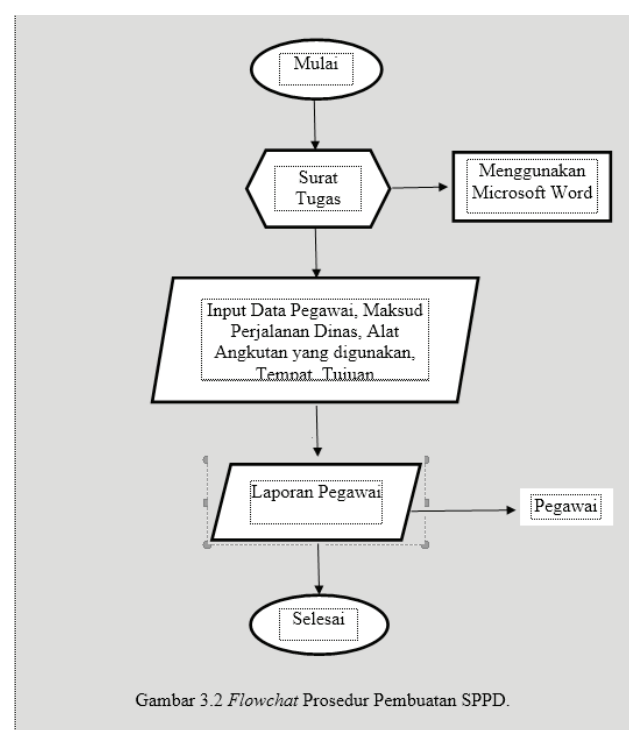

Gambar 2 Sistem Berjalan Pembuatan Surat Perintah Perjalanan Dinas

\section{Sistem Baru Yang Diusulkan}

Berdasarkan hasil analis permasalahan maka diusukan sistem baru yang digambarkan secara lengkap dalam Diagram Use Case. Berikut Diagram Use Case sistem yang diusulkan Gambar 3.

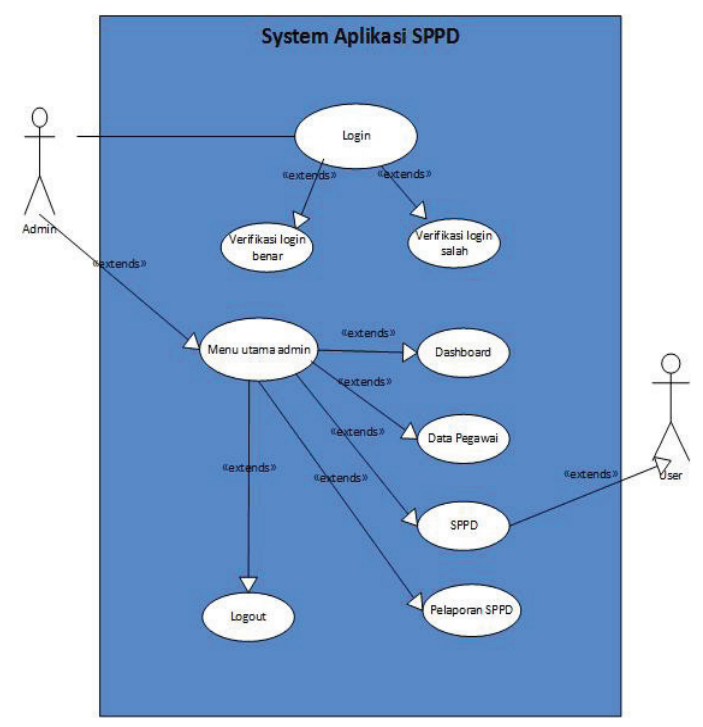

Gambar 3 diagram use case aplikasi Surat Perintah Perjalanan Dinas 
Tabel 1 Definisi Use Case

\begin{tabular}{|c|l|l|}
\hline No. & \multicolumn{1}{|c|}{ Use Case } & \multicolumn{1}{c|}{ Deskripsi } \\
\hline 1. & Login & Merupakan proses untuk melakukan login/masuk pengguna dari sistem. \\
\hline 2. & Logout & $\begin{array}{l}\text { Merupakan proses untuk melakukan logout/keluar pengguna dari } \\
\text { sistem. }\end{array}$ \\
\hline 3. & Dashboard & Melihat Statistik SPPD \\
\hline 4. & Mengelola pengguna & Mengelola semua data pengguna (user) \\
\hline 5. & Mengelola Pegawai & Merupakan proses memasukkan data pegawai \\
\hline 6. & Mengelola SPPD & Merupakan proses memasukan, merepisi data SPPD \\
\hline 7. & Pelaporan SPPD & $\begin{array}{l}\text { Setelah selesai melakukan perjalanan dinas wajib membuat laporan } \\
\text { hasil perjalanan dinas }\end{array}$ \\
\hline 8. & Lithat SPPD & Merupakan seluruh Arsiv dari SPPD \\
\hline 9. & Administrator & $\begin{array}{l}\text { Merupakan manajemen dari sistem aplikasi SPPD meliputi: a) } \\
\text { manajemen User; b) manajemen backup/restore database, Log CRUD, } \\
\text { System Setting. }\end{array}$ \\
\hline
\end{tabular}

\section{Diagram Activity User Login}

Pada diagram activity login user memasukan username dan password terlebih dahulu jika tidak valid sistem akan menginformasikan kesalahan inputan dari user. Jika username dan password valid maka sistem akan otomatis kedalam halaman utama.

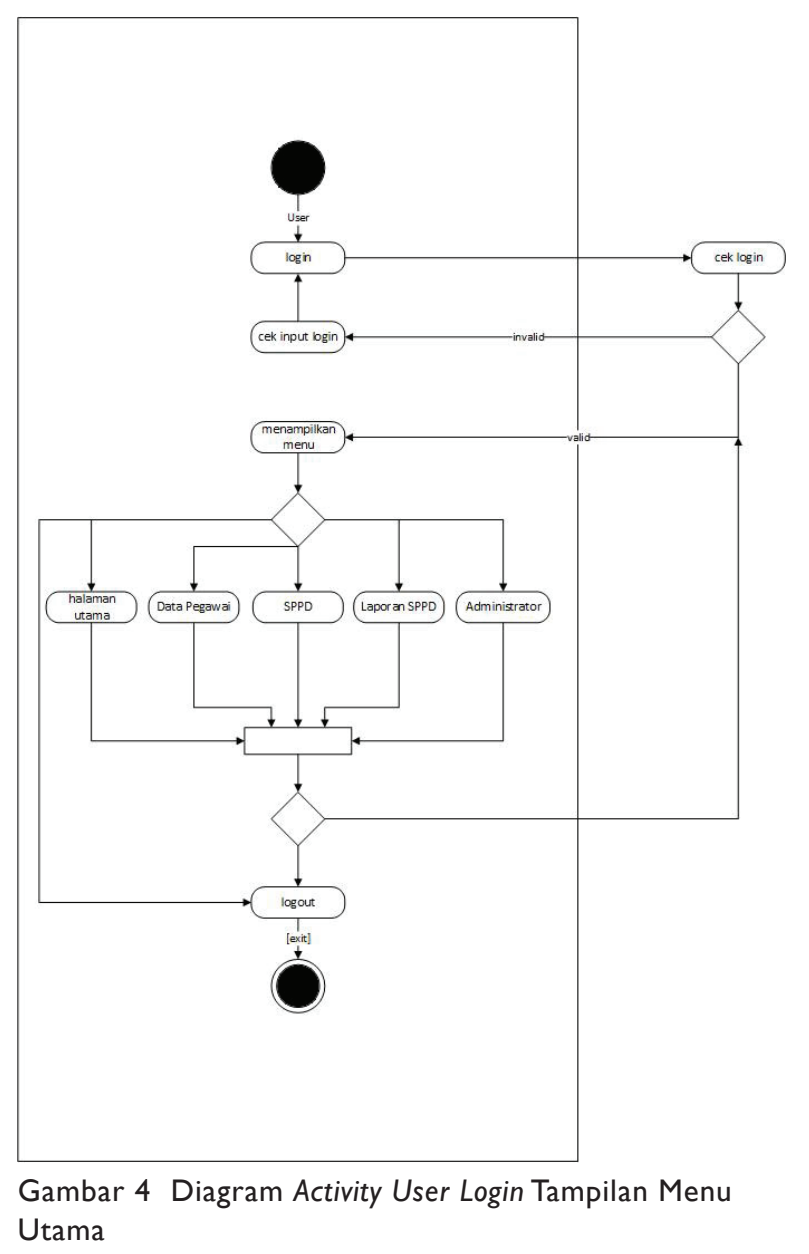

\section{Perancangan Basis Data}

Rancangan database dipakai untuk mempermudah dalam proses penyeleksian data, serta membantu pemprograman dalam mengambil dan menampilkan data. Pada database digunakan tabel-tabel, dan pada tabeltabel ini akan dijelaskan nama field, type dan size mengenai data tersebut, dapat dilihat pada Gambar 5.

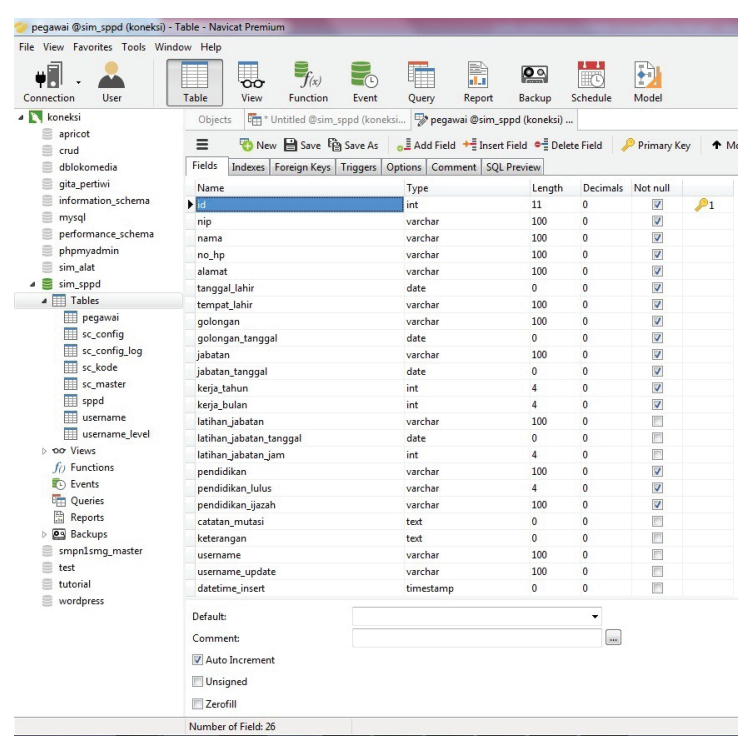

Gambar 5 Perancangan Database

\section{Implementasi Perangkat Keras dan Perangkat Lunak}

\section{Perangkat Keras (Hardware)}

Perangkat keras yang digunakan untuk pembangunan aplikasi ini adalah sebuah komputer dengan spesifikasi: 
a. Processor Intel(R) Core (TM) i5 CPU M520 @2.4 GHz

b. Hardisk 320 GB 5400-rpm

c. RAM 2 GB

d. VGA Intel Graphics Media Accelerator (GMA) HD

e. LCD Monitor 14.1", 1280x800 pixels

f. Printer tinta sebagai alat pencetak output sistem yang berupa laporan (report) yang memiliki kemampuan untuk mencetak dengan ukuran kertas A4 dan F4

Spesifikasi minimum penggunaan aplikasi ini dapat digunakan pada komputer yang memiliki minimum spesifikasi perangkat keras sebagai berikut:
a. Processor Intel Atom $1.8 \mathrm{GHZ}$
b. RAM $1 \mathrm{~GB}$
c. Hardisk $160 \mathrm{~GB}$
d. VGA Integrated

\section{Perangkat Lunak (Software)}

Piranti lunak yang digunakan pada pembangunan aplikasi ini:

a. Microsoft Windows 7 Professional Service Pack 1, 32 bit sebagai platform sistem operasi dalam pengembangan aplikasi

b. AMPP Web Server Version 1.7.3 sebagai webserver

c. MySQL Database Version 5.1.41 sebagai DBMS

d. phpMyAdmin Version 3.2.4 sebagai Database Manager.

e. Aplikasi Web Browser yaitu Firefox

f. Notepad ++ Version 6.6.1 sebagai text editor untuk coding (menuliskan source code PHP)

g. Aplikasi Dreamweaver

h. Aplikasi Microsoft Excel untuk menampilkan report.

i. Aplikasi Adobe Potoshop CS6 untuk mendesain tampilan aplikasi

\section{Hasil Implementasi Antarmuka}

\section{Halaman Login}

Halaman yang akan ditampilkan pertama kali ketika user mengetikkan alamat sistem aplikasi SPPD pada tahap pemeriksaan pada browser. Halaman Login adalah form yang digunakan ada beberapa yang membedakan hak akses antara user yang satu dengn yang lain. Perbedaannya dapat dilihat pada menu-menu yang nantinya akan ditampilkan jika user mempunyai username dan password yang valid guna mengakses aplikasi. Tampilan dari halaman login seperti pada gambar 6 di bawah ini.
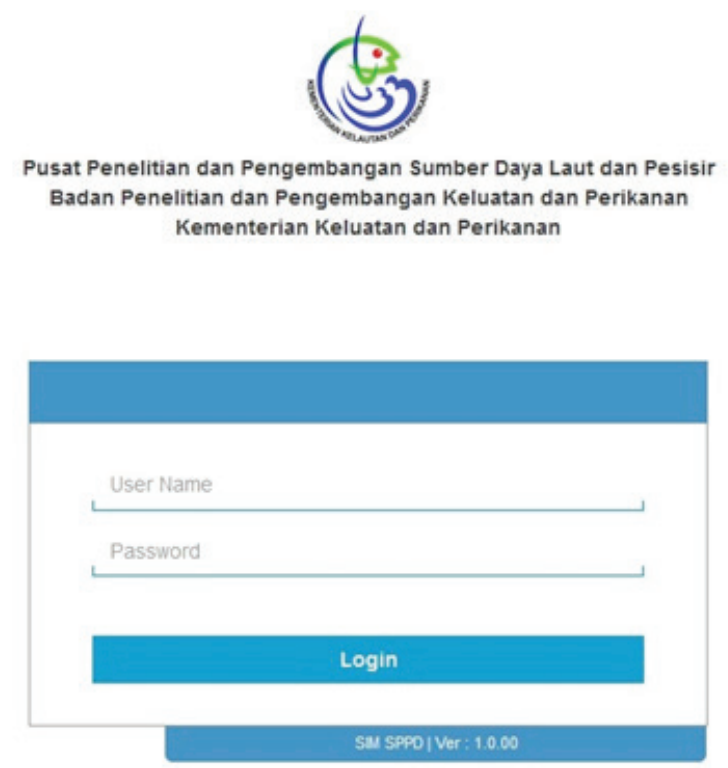

Gambar 6 Halaman Login

\section{Halaman Menu Utama}

Halaman pertama kali yang akan ditampilkan jika user mempunyai username dan password yang valid untuk login ke aplikasi dan sistem berhasil menverifikasinya. Tampilan dari halaman Utama/Dashboard bisa dilihat pada Gambar 7 di bawah ini.

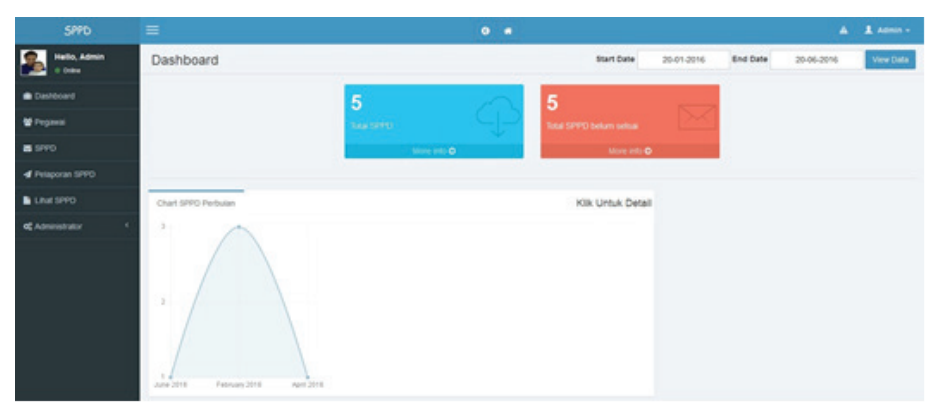

Gambar 7 Halaman Menu Utama

Pada halaman utama ini menampilkan statistik jumlah total surat perintah perjalanan dinas (SPPD) yang belum selesai dan yang telah selesai dikerjakan. Statistik ditampilkan dalam bentuk grafik perbulan dan dalam bentuk grafik pie untuk detailnya. Pada module Dashboar ini terdiri dari tiga file php. 


\section{Halaman Pegawai}

Menampilkan data terkait Pegawai pada

Pusat Penelitian dan Pengembangan Sumber

Daya Laut dan Pesisir. Tampilan bisa di lihat pada gambar 8 di bawah ini.

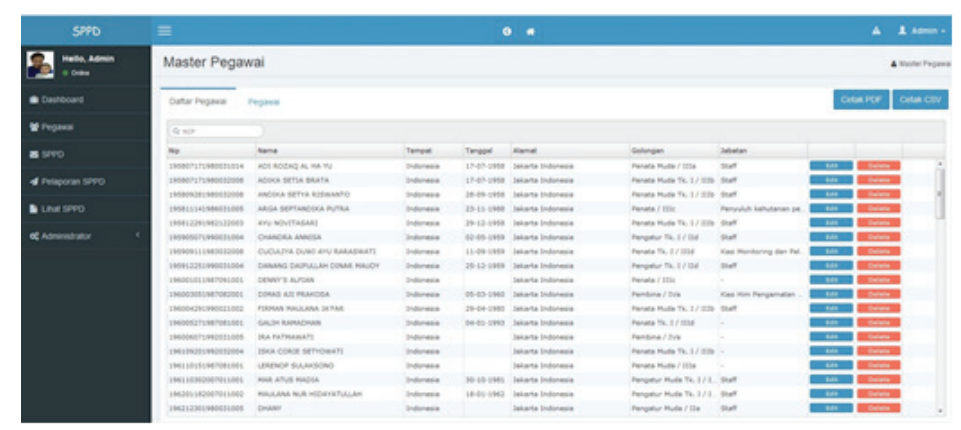

Gambar 8 Halaman Pegawai

\section{Halaman Input Pegawai}

Halaman yang ditunjukan Input data Pegawai bisa dilihat pada gambar 9 .

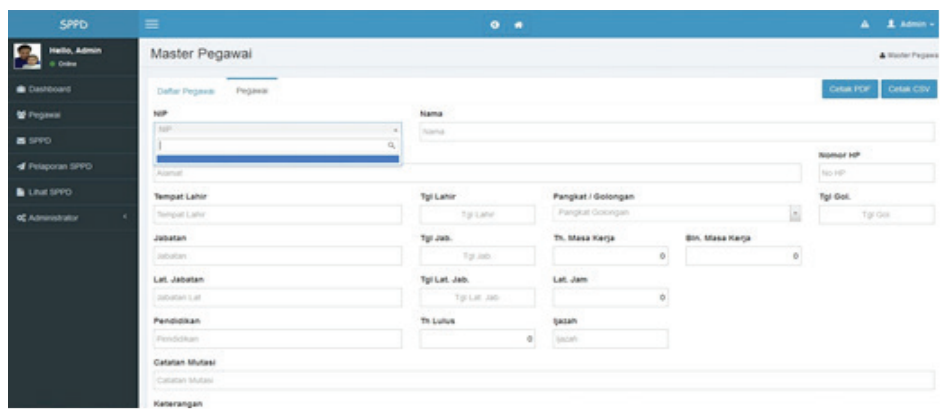

Gambar 9 Halaman Input Pegawai

\section{Halaman SPPD}

Menampilkan data Surat Perintah Perjalanan Dinas (SPPD). Tampilan bisa di lihat pada gambar 10 di bawah ini:

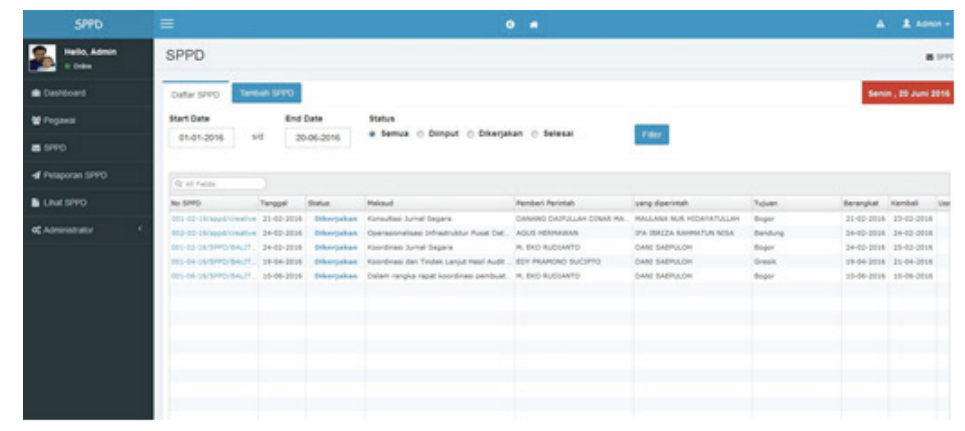

Gambar 10 Halaman SPPD

\section{Halaman Input SPPD}

Menampilkan data pengimputan terkait Surat Perintah Perjalanan Dinas (SPPD). Tampilan bisa di lihat pada gambar 11 di bawah ini:

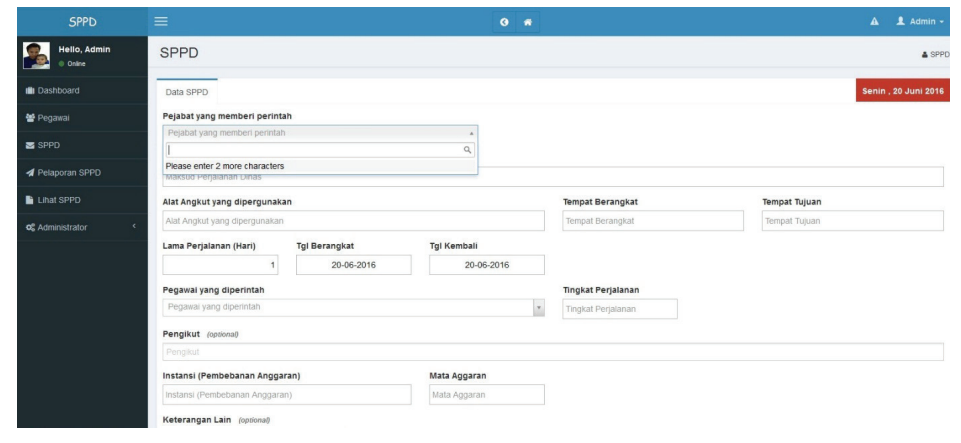

Gambar II Halaman Input SPPD

\section{Halaman Input Pelaporan}

Menampilkan Input data pelaporan terkait perjalanan dinas. Tampilan bisa di lihat pada gambar 12 di bawah ini:

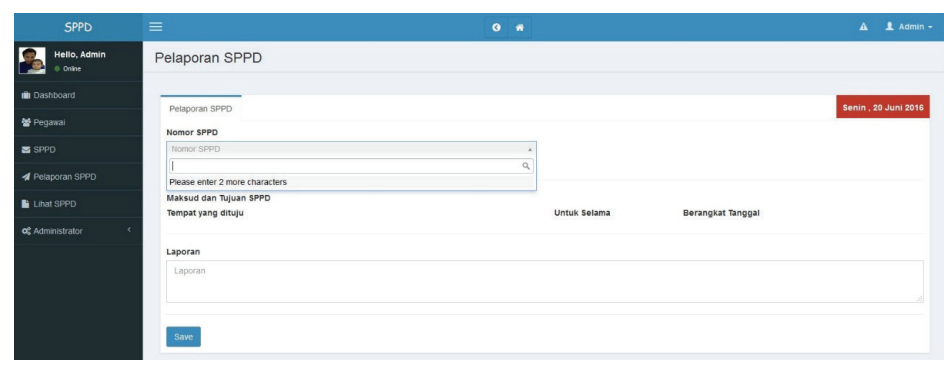

Gambar 12 Halaman Input Pelaporan

\section{Pengujian Sistem}

Setelah tahap implementasi hasil rancangan sistem dilakukan, maka tahap selanjutnya adalah melakukan pengujian terhadap sistem. Pengujian terhadap sistem dilakukaan dengan uji fungsionalitas menggunakan metode Black-Box Test dan White-Box Test.

\section{Black-Box Test}

Black-Box Test yaitu pengujian yang berfokus pada persyaratan fungsional suatu piranti lunak dengan membuat himpunan kondisi input yang akan melatih seluruh syarat-syarat fungsional sistem. Tabel 2 di bawah ini merupakan hasil uji coba yang telah dilakukan terhadap sistem, berupa deskripsi fungsi-fungsi dari menu pada aplikasi serta menunjukkan kesesuaian fungsi yang dihasilkan ketika dilakukan pengetesan. Dari hasil uji coba tersebut dapat dilihat bahwa semua fungsi yang diharapkan telah dapat tercapai, ditandai dengan keterangan 'Berhasil' pada kolom 'Hasil Aktual'. 
Tabel 2 Black-Box Test

\begin{tabular}{|c|c|c|c|c|}
\hline No & $\begin{array}{l}\text { Nama } \\
\text { Fungsi }\end{array}$ & Deskripsi & Hasil yang Diharapkan & $\begin{array}{l}\text { Hasil } \\
\text { Aktual }\end{array}$ \\
\hline 1. & Login & $\begin{array}{l}\text { User yang ada di sistem } \\
\text { memasukkan username } \\
\text { dan password sesuai hak } \\
\text { aksesnya dan masuk sistem }\end{array}$ & $\begin{array}{l}\text { Pengguna dapat melakukan login ke dalam } \\
\text { sistem dan mengakses menu yang ada di } \\
\text { dalam sistem sesuai dengan hak user. }\end{array}$ & Berhasil \\
\hline 2. & Input Data & $\begin{array}{l}\text { Pengguna menginput isian } \\
\text { data-data yang diperlukan } \\
\text { ke dalam sistem dan akan } \\
\text { dilakukan validasi. }\end{array}$ & $\begin{array}{l}\text { Ketika User memasukkan data ke dalam } \\
\text { sistem maka akan dilakukan cek validasi } \\
\text { secara interaktif oleh sistem. Hasil akhir } \\
\text { data tidak terdapat kesalahan/error }\end{array}$ & Berhasil \\
\hline 3. & $\begin{array}{l}\text { Manipulasi } \\
\text { data }\end{array}$ & $\begin{array}{l}\text { Pengguna dapat menambah, } \\
\text { mengubah dan menghapus } \\
\text { data. Data yang tersedia } \\
\text { dalam aplikasi yaitu Pegawai, } \\
\text { SPPD, Laporan dan } \\
\text { Administrator. }\end{array}$ & $\begin{array}{l}\text { Ketika pengguna menambah, mengubah } \\
\text { atau menghapus master maka akan } \\
\text { dilakukan manipulasi data tidak ada } \\
\text { kesalahan }\end{array}$ & Berhasil \\
\hline
\end{tabular}

\section{White-Box Test}

\section{Pengujian Login}

Menguji seluruh proses login dari mulai memasukan username dan password apakah benar atau tidak. Ketika tidak benar akan muncul pesan kesalahan, jika benar akan otomatis masuk kedalam system gambar 13 .

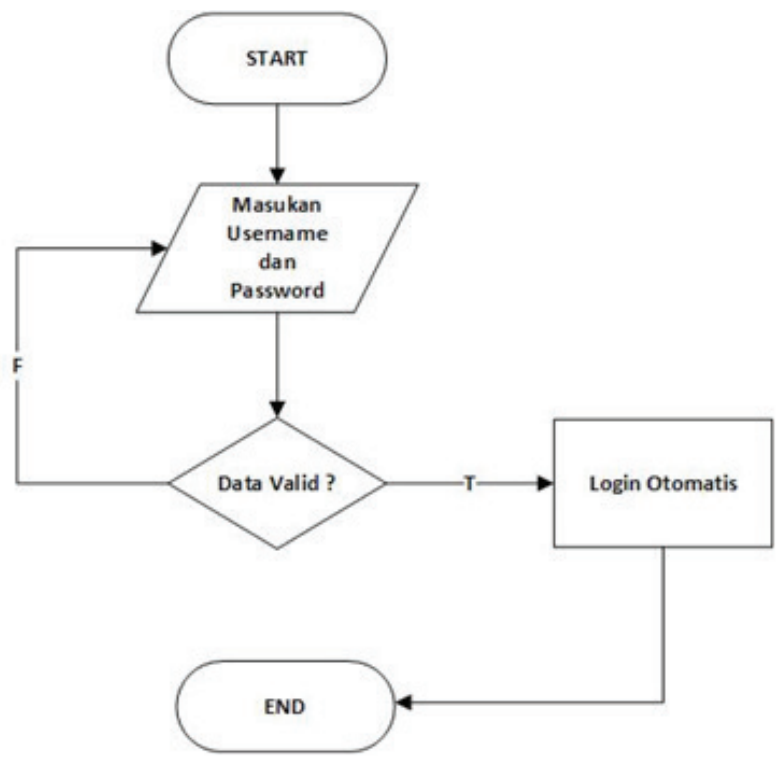

Gambar 13 White Box Testing Login

\section{Pengujian Input Data Pegawai}

Pengujian pada input data, apakah data yang dimasukan sesuai dengan data yang sudah ditetapkan, sistem akan memvalidasi masukan dari user, dan hasilnya sesuai dengan data yang telah di tetapkan dapat dilihat pada gambar 14

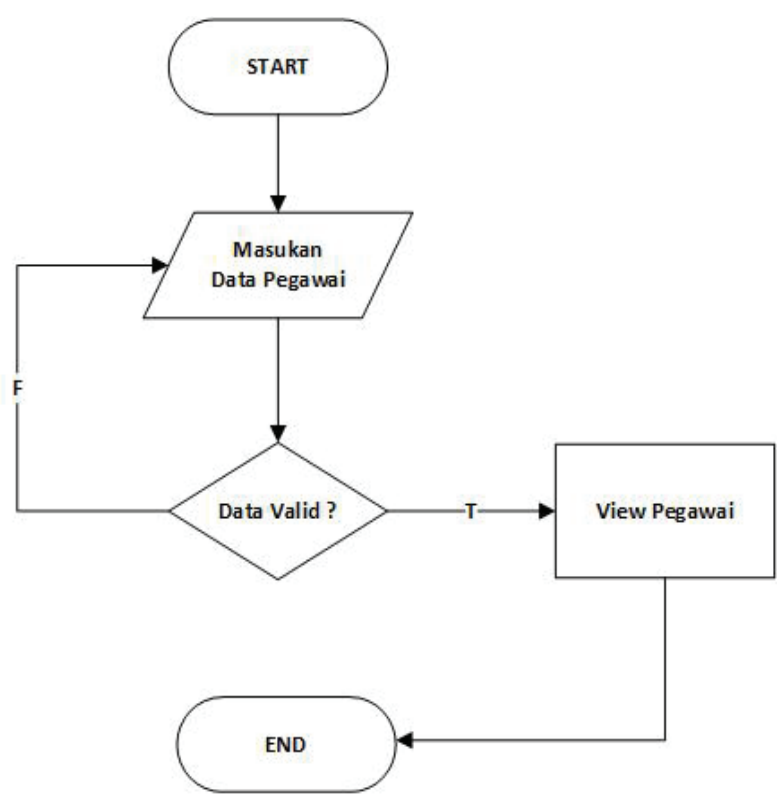

Gambar 14 White Box Testing Input Data Pegawai

\section{Pengujian Input data SPPD}

Pengujian pada input data SPPD, apakah data yang dimasukan sesuai dengan data yang sudah ditetapkan, sistem akan memvalidasi masukan dari user, dan hasilnya sesuai dengan data yang telah di tetapkan dapat dilihat pada gambar 15 


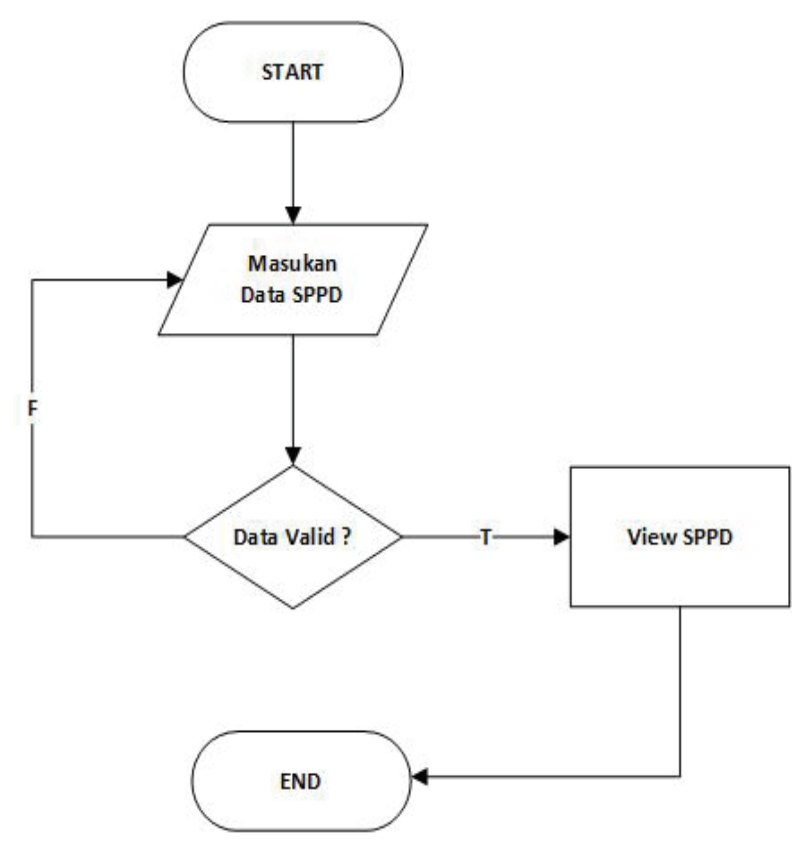

Gambar 15 White Box Testing Input Data SPPD

\section{Pengujian Input Laporan}

Pengujian pada input data Laporan, apakah data yang dimasukan sesuai dengan data yang sudah ditetapkan, sistem akan memvalidasi masukan dari user, dan hasilnya sesuai dengan data yang telah di tetapkan dapat dilihat pada gambar 16 .

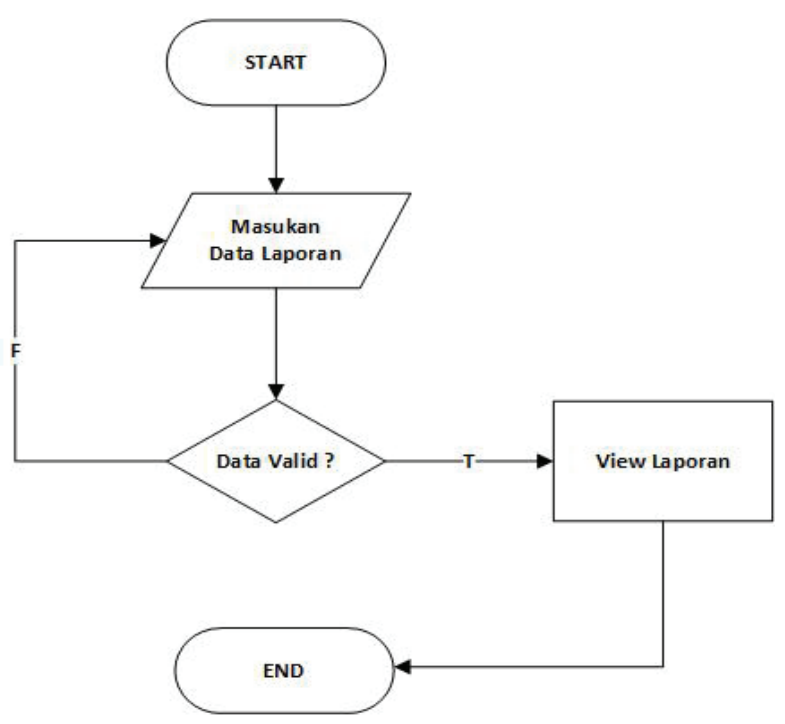

Gambar 16 White Box Testing Input Laporan

\section{EVALUASI SISTEM}

Dalam pembangunan sebuah sistem, terkadang tidak semua hal yang telah direncanakan, dianalisis dan dirancang dapat diimplementasikan dengan baik. Berikut akan dijelaskan beberapa hal baik yang berhasil di implementasikan pada sistem (kelebihan sistem) maupun yang kurang berhasil diimplementasikan pada sistem (kekurangan sistem).

\section{Kelebihan Sistem}

a. Sistem keamanan lebih terjamin karena sudah menggunakan authentifikasi username dan password sehingga hanya user yang mempunyai account saja yang dapat mengakses aplikasi.

b. Tampilan aplikasi yang dibuat menggunakan Bootstrap akan menyesuaikan ukuran layar dari Browser yang digunakan baik di desktop, tablet, ataupun mobile device.

\section{Kekurangan Sistem}

a. Sistem aplikasi ini belum terintegrasi dengan sistem lainnya yang ada di Kementerian Kelautan dan Perikanan seperti Sistem Informasi Kepegawaian (SIMPEG).

b. Untuk biaya dan anggaran perjalanan dinas belum terkoneksi dengan sistem keuangan.

c. Belum adanya report evaluasi pengambilan keputusan pimpinan.

\section{SIMPULAN DAN SARAN}

\section{A. Simpulan}

Berdasarkan hasil dari analisa, perancangan, dan implementasi, maka didapatkan beberapa kesimpulan sebagai berikut :

1. Hasil penelitian telah membangun Aplikasi Surat Perintah Perjalanan Dinas (SPPD)

2. Dengan Sistem Aplikasi Surat Perintah Perjalanan Dinas (SPPD) telah terpetakan alur proses pembuatan SPPD lebih singkat

3. Pencarian data surat SPPD laporan kepada pimpinan di Bagian Tata Usaha dapat dengan mudah, cepat, dan akurat serta untuk pertanggungjawaban staf palaksana kepada pimpinan terkait dalam pembuatan surat. 


\section{B. Saran-saran}

Pengembangan sistem ini belum sepenuhnya maksimal ada beberapa module yang harus dikembangkan kedepannya yaitu :

1. Sebaiknya Aplikasi Surat Perintah Perjalanan Dinas (SPPD) dintegrasikan dengan sistem Kepegaian Kementerian Kelautan dan Perikanan agar lebih dinamis membaca data.

2. Agar lebih efisien module biaya perjalanan dinas membaca langsung dar sistem keuangan.

3. Untuk pengembangan kedepannya Aplikasi Surat Perintah Perjalanan Dinas (SPPD) untuk perangkat mobile.

\section{DAFTAR PUSTAKA}

Kadir, Abdul. 2004. Dasar Pemrograman Java ${ }^{\mathrm{TM}}$ 2., Andi Offset., Yogyakarta.

Buku Pintar jQuery dan PHP, Mediakom: 2011

Laporan Akhir Dokpus. 2015. Perpustakaan Digital. Pusat Penelitian dan Pengembangan Sumber Daya Laut dan Pesisir.

Bunafit Nugroho, 2004, PHP dan MYSQL Dengan Editor Dreamweaver MX, Andi, Yogyakarta.

Roger, S. Pressman, Ph.D., 2012, Rekayasa Perangkat Lunak (Pendekatan Praktisi) Edisi 7 : Buku 1 ", Yogyakarta: Andi.

Rangkuti, F. 2004, Analisis SWOT Teknik Membedah Kasus Bisnis, PT. Graedia, Jakarta
Rosa, A.S. dan Salahuddin., 2013, Rekayasa Perangkat Lunak, Terstruktur dan Berorientasi Objek, Informatika: Bandung.

Saputra, A. 2013, Smarty, PHP OOP Engine for PHP Template, Elex Media Komputindo: Jakarta.

Yasin, V. 2012, Rekayasa Perangkat Lunak Berorientasi Objek, Pemodelan Arsitektur dan Perancangan (Modeling, Architecture and Design), Mitra Wacana Media: Jakarta.

Wiswakarma, K. 2010, Panduan Lengkap Menguasai Pemrograman CSS, Loko Media: Yogyakarta.

http://www.markijar.com/2015/04/kelebihandan-kekurangan-model-proses.html, 6 Desember 2017

http://pusriskel.litbang.kkp.go.id/index.php, 10 April 2016, 10:31

https://id.wikipedia.org/wiki/Surat, 19 April 2016 12:54

http://id.wikipedia.org/wiki/Web_server, 14 Mei $\underline{2016,22: 54}$

http://www.pengertianku.net/2015/09/pengertianuml-dan-jenis-jenisnya-serta-contohdiagramnya.html), 3 April 2016 11:05 